\title{
10 health stories that mattered: May 19-23
}

- Canada received a grade of D- in the 2014 Active Healthy Kids Canada report card, placing 12th out of 15 countries with report cards on the health of children and youth. Though $84 \%$ of 3- to 4-year-olds in Canada get the recommended 180 minutes of daily physical activity, only $7 \%$ of 5to 11 -year-olds and $4 \%$ of 12 - to 17 -year-olds meet guidelines recommending 60 minutes of moderate to vigorous activity each day.

- Health care facilities should remind front-line staff to wear protective equipment when caring for feverish, coughing patients in light of cases of Middle East respiratory syndrome (MERS) in the United States, recommends Infection Prevention and Control Canada. Screening of patients exhibiting possible symptoms of acute respiratory illnesses should include collecting their recent travel history (10-14 days) and that of the people around them.

- The federal government has promised $\$ 36$ million to help fund research in nine African countries to improve health care for mothers, newborns and children. The announcement comes in the lead-up to an international summit on maternal, newborn and child health to be held May 28-30 in Toronto.

- The first clinical trial of medical marijuana to be registered with Health Canada was filed by Prairie Plant
Systems Inc., the parent company of Saskatchewan-based CanniMed Ltd. An application was approved for a "randomized, double blind, placebo controlled, proof-of-concept, crossover clinical trial of vapourized cannabis in adults with painful osteoarthritis of the knee."

- Forged authorizations for medical marijuana prompted Health Canada to beef up security and increase bureaucracy to prevent fraud, reports the CBC. Last year, at least five doctors had their signatures forged on applications for medical marijuana.

- There is an association between improved health outcomes and fitness levels, according to a report from Statistics Canada based on the Canadian Health Measures Survey. All health outcomes studied (except systolic blood pressure) were significantly better in respondents whose cardiorespiratory fitness was "excellent" compared with those whose scores were "needs improvement."

- Health Canada is seeking input from patients, health care providers and the public on its approach to drug shortage notification. The current system, launched in March 2012, is voluntary, but "Canadian manufacturers and importers are expected to post all anticipated and actual drug shortages and discontinuances" as early as possible.
- Health care promises are being made by candidates campaigning for the upcoming Ontario election. NDP Leader Andrea Horwath has pledged to cut emergency department wait times by half, hire 250 nurse practitioners, open 50 new 24-hour family health clinics and create 1400 new long-term care beds. Liberal Leader Kathleen Wynne has promised to expand the powers of nurses and nurse practitioners, allowing registered nurses to prescribe certain medications and nurse practitioners to order some diagnostic tests.

- Researchers from the University of Montréal have developed a faster method of detecting fake erectiledysfunction drugs. The "rapid, quantitative liquid chromatographymass spectrometry screening method" takes 10 minutes - five times faster than the method used by Health Canada - and can detect low concentrations of potentially toxic compounds.

- A 10-year-old Ontario girl with leukemia should not be removed from her family and forced to resume chemotherapy, decided the Children's Aid Society of Brant, Ontario. The girl, who is from New Credit First Nation, quit chemotherapy because of the adverse effects and has turned to traditional Aboriginal medicine. — Roger Collier, CMAJ

CMAJ 2014. DOI:10.1503/cmaj.109-4816 